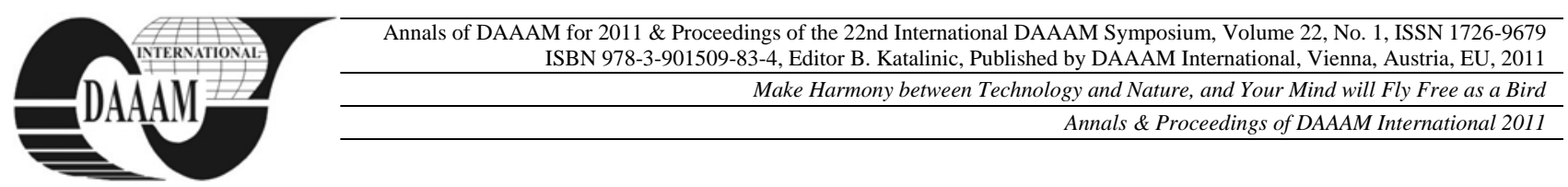

\title{
IMPROVING THE PROCESSES OF AUDITING THE QUALITY MANAGEMENT SYSTEM
}

\author{
JAMBOR, J[aroslav] \& MAJERIK, J[ozef]
}

\begin{abstract}
The authors describe the process of auditing the quality management system service partners SEAT brand. They Demonstrate continuous improvement of service quality by implementing the management system. Opportunities to improve service quality are determined from the results of external audits of QMS. Audit activities and the sequence of steps were carried out in accordance with ISO 19011. SSQMS main tool was a checklist of questions. This list contained all the standards for service partner and work to simplify these standards as defined by issues. Through the quality of external audits carried out to improve business results.

Key words: process, activities of the audit, service, automotive industry, improvement, seat service quality management system "ssqms"
\end{abstract}

\section{INTRODUCTION}

The audit process must be efficient and be a reliable tool to support policy management and company management. At the same time be satisfied the following requirements for auditors: ethical conduct, fair presentation, professional care, independence and evidence-based approach (ISO 19011).

Principles of audit procedures were followed in the implementation of external audits by auditors of the company comply with TÜV SÜD Automotive GmbH, Munich. Processes were auditing in companies providing services and sale of SEAT cars. The new EU regulation has resulted in the implementation of new quality management system on the market service "after sales", services of cars - SEAT Service Quality Management System, SSQMS. That is a system of SSQMS has been audited and continuous improvement. The question was whether a system of quality management will increase the efficiency of the company. The second question was whether the auditing is effective.

\section{ACTIVITIES OF THE AUDIT}

The audit consisted of the following seven steps.

1) Starting audit:

-Appointing the head of the audit team

-Defining the audit objectives, audit scope, audit criteria

-Determination of audit methods

-Selection of audit team

-Establishing initial contact with the audited company

-Determine the possibility of audit

2) Performance review documents:

-Review of the QMS documents, including review of records with respect to audit criteria

3) Preparing for the audit work performed at the site:

-Preparing the audit plan

-Referral to the audit team

-Preparation of working documents

4) Implementation of activities on-site audit of the company: -Implementation of the opening meeting

-Communication during the audit
-Roles and responsibilities of guides

-Verification of the information collection

-Formulation of audit findings

-Preparing audit conclusions

-Implementation of the final meeting and evaluation of audit

5) Preparation, approval and distribution of audit reports:

-Preparation of the audit report

-Approval and distribution of audit reports

6) Closure audit

7) Realize activities after completion of the audit (ISO 19011)

After a successful audit has been certified service partner of the Quality Management System and ISO 9001 certificate as required by the manufacturer, so. SSQMS certificate. SSQMS main tool was a checklist of questions. This list contained all the standards for service partner SEAT and work to simplify these standards as defined by issues.

The checklist is divided into individual processes that are defined for an authorized service center SEAT and is divided into the following five areas:

1) Buildings

2) Management, processes, organization and personnel

3) Contact place of customers

4) Spare parts

5) Workshop

This division greatly facilitates the work of service, particularly in introducing SSQMS in practice and in defining the various remedial measures in improving quality. A checklist of questions is also a self-assessment tool for our service partners, as it will allow any time to check compliance with the requirements of quality management system. SSQMS system serves only to check compliance with prescribed standards, which are given by the manufacturer. As mentioned above from the view of these tests are performed by an independent service provider - TÜV SÜD Automotive GmbH. It also contains a checklist of criteria "questions" are not defined as a manufacturer of quality "standards", ie. that service partner in the audit does not meet these criteria. These criteria call or optional recommended.

Failure criteria, optional service partner partial lost competitive advantage in servicing the market (SEAT S.A., 2003). SSQMS main tool is a checklist of questions. This list contained all the standards for service partner for SEAT and simplification of work are defined by standards issues. This checklist is based on individual processes is called the check list (Jambor et al., 2010).

\section{PERFORMANCE EVALUATION AUDIT SSQMS}

The first positive results from the introduction of SSQMS service partners were visible after two years of operation. Significant improvement in the quality of sales-service posts were seen after four SSQMS existence, which was documented in the results of the evaluation of customer satisfaction CSS Customer Satisfaction Survay and the results of the evaluation of satisfaction dealers DSS - Dealer Satisfaction Survay. CSS and DSS are directly linked and related analysis of customer 
satisfaction and dealers, as if it is satisfied then the ultimate customer satisfaction and dealer of vehicles of a particular brand because it has provided increased sales of its products. The gradual improvement of customer satisfaction are documented after the third and fourth flow there SSQMS in the following Tables no. 1 with bar chart.

\begin{tabular}{|c|c|c|}
\hline $\begin{array}{c}\text { Slovakia SEAT } \\
\text { code }\end{array}$ & Year 2006 & Year 2007 \\
\hline SK005 & 88,6 & 56,0 \\
\hline SK008 & 83,1 & 89,3 \\
\hline SK036 & 61,4 & 55,8 \\
\hline SK037 & 76,1 & 83,7 \\
\hline SK038 & 90,0 & 81,0 \\
\hline SK040 & - & 89,3 \\
\hline SK042 & 86,1 & 82,9 \\
\hline SK043 & 64,3 & - \\
\hline SK044 & 86,2 & 100,0 \\
\hline SK046 & 81,0 & 71,8 \\
\hline SK047 & 92,9 & 96,4 \\
\hline SK048 & 73,3 & 100,0 \\
\hline SK049 & 94,8 & 102,5 \\
\hline SK051 & 74,2 & 83,2 \\
\hline SK052 & 82,7 & 79,1 \\
\hline SK056 & 71,0 & 62,0 \\
\hline SK057 & 69,5 & 81,4 \\
\hline SK059 & 76,4 & 93,5 \\
\hline SK060 & 91,9 & 76,8 \\
\hline SK064 & 71,0 & 89,3 \\
\hline SK066 & 90,3 & 79,4 \\
\hline SK067 & 75,8 & 57,1 \\
\hline SK069 & - & 80,0 \\
\hline MEAN & 80,03 & 13,49 \\
\hline STANDARD & 9,72 & \\
DEVIATION & -58 \\
\hline S10vakas & SEAT, & \\
\hline
\end{tabular}

Tab. 1. Slovakia, CSS SEAT, STAGE 2006, before entire network and 2007, after the entire network (TÜV SÜD Automotive GmbH Munich, 2007)

The results indicate that customer satisfaction grow in the last analyzed in 2007 - results have been comprehensively evaluated in 2008 for the previous year 2007 - of 2.7 percent compared with 2006. Overall, the reference years 2004 to 2007 was to increase customer satisfaction by 12.8 percent, a substantial improvement in the quality of products. Those partners who introduced SSQMS not only because of concerns about the withdrawal of licenses for service activities, but also because of the streamlining and simplification activities in service and sales should increase profitability by an average of $3 \%$ to $10 \%$. Overall improvement of the system shown in particular:

- Reduction in customer complaints;

- Increase in the number of passage guides through service;

- Increase in the number of vehicle sales, or retaining the original volume of sales in the sharp increase in competition from other brands - Suzuki, Hyundai, Kia, etc.;

- Transparency of the accountability of staff engaged in various activities;

- The clarity of documentation and records the execution of all activities;

- Increase customer satisfaction and trust from customers.

For those service partners, who have not been consistent in implementing SSQMS experienced following shortcomings:
- Well-documented records of staff training;

- Differences in education planning staff to the standards and importer of SEAT;

- Lack of special tools, fixtures and equipment workshop;

- Not fully implemented activities related to convening and service actions;

- Lack of special preparation and calibration tools;

- Failure of telephone contacts with customers, following receipt of the vehicle from service, or just the formalization of this activity.

Some service partners have tried to introduce SSQMS only paper - certificate. They understand the system and there has been no improvement in them after four years. Losing customers and got into financial problems.

Service partners who have implemented SSQMS not only for its issue, but also to simplify and streamline the system has the advantage of maintaining the market share or expansion of sales and service vehicles.

\section{CONCLUSION}

Based on the experience of the audit indicates that the quality management system is beneficial only if:

a) practical - is tailor-made and suitable for business managers achieve the intended results - all activities are facilitated, all materials and information can be found immediately, each employee knows what to do, how to do, is set out clearly substitution and competencies,

b) economic - the ultimate aim of introducing a system of quality management and business is to achieve a positive profit -reduce costs, increase sales, increase profitability,

c) documented - is processed quality policy, quality objectives, quality manual, card processes, documented procedures, records - each action is recorded and described, signed by the responsible person making the actual performance ...,

d) continuous improvement - the improvement of all activities and everything in the company can improve the ever-changing needs and customer requirements continuous collection of views of customers regarding their satisfaction and ideas for process improvement.

If the management of service partners and sales for cars understand interconnection link above, then be motivated to implement quality management systems not only technically but also from the pragmatic. Finally, SSQMS that is practical, economical, documented, and constantly improving service brings many benefits to partners who can correctly understand and implement (Jambor, 2010). Continuously improve the quality of external we can progressively improve QMS in the future - this will be the subject of research in the future.

\section{REFERENCES}

SEAT S.A. (2003). Handbook Service Organization. Ref. OSA248070 - Internal Materials, Barcelona - Spain.

ISO 19011:2002, Guidelines for quality and/or environmental management system auditing

Jambor, J. (2010). Analysis of the results of audits of quality management system - sales service of cars. Quality Innovation prosperity,TnUAD Trencin, Slovak Republic, Vol. XIV, No. XIV/1-2-2010, pp 1-8, ISSN1335-1745

TÜV SÜD Automotive GmbH Munich (2007). Internal Materials, Munich - Germany

Jambor, J. et al. (2010). Increasing quality of services by implementation of quality management system in car market dealers, Annals of DAAAM for 2010 \& Proceedings of the 21st International DAAAM Symposium, 20-23rd October 2010, Zadar, Croatia, ISSN 1726-9679, ISBN 9783-901509-73-5, Katalinic, B.(Ed.), pp. 0621-0622, Vienna, Austria 